\title{
Üç hücreli motif genelleme ile oluşturulan kü̧̈ük ölçekli biyolojik sinir ağlarının bellek davranışı
}

\author{
Ahmet TURAN"1,*, Temel KAYIKÇIOĞLU ${ }^{2}$ \\ ${ }^{1}$ Kastamonu Üniversitesi Mühendislik ve Mimarlık Fakültesi, Elektrik ve Elektronik Mühendisliği \\ Bölümü, Kastamonu \\ ${ }^{2}$ Karadeniz Teknik Üniversitesi, Mühendislik Fakültesi, Elektrik- Elektronik Mühendisliği Bölümü, \\ Kanuni Kampüsü, Trabzon
}

Geliș Tarihi (Received Date): 29.11.2018

Kabul Tarihi (Accepted Date): 04.03.2019

\section{Özet}

Biyolojik bellek yapısını ve fonksiyonlarını anlamak için teorik ve deneysel pek çok çalışma yapılmaktadır. Bu çalışmalarda biyolojik ă̆ların, özel hücreler arası bağlantılardan (motifler) oluştuğu görülmüsştür. Deneysel çalışmalar ışı̆ğında oluşturulan modeller üzerinde, biyolojik ăglardan oluşan bellek yapıları ve bu yapıların temel yapı taşı olan motifler incelenmektedir. Çalışmamızda sinir hücresi, sadece soma bölümünden oluşan ve tek bölmeli hücre şeklinde modellendi. Hücreler arası iletişim kimyasal sinaps şeklinde tercih edildi ve modelde hücreler arası iletişim incelendi. Hücre rolleri giriş, ara ve çıklş olarak düşünülen üç hücreli motiflerde, uzun -ve kısa dönem bellek davranışı çalışıldl. Üç hücreli motiflerin giriş, ara ve çıkış hücrelerinin çoklanması yöntemiyle oluşturulan (motif genelleme) küçük ölçekli biyolojik ağların, uzun -ve kisa dönem bellek davranışlar tespit edildi. Motiflerde ve motiflerden oluşan ă̆larda yaptı̆̆ımız çalışmalardan elde edilen bulgular karşılaştırıldı. Biyolojik ağın, kendisini oluşturan motiflerle aynı bellek davranışını sergilediği gösterildi. Böylece biyolojik ağların bellek davranışlarını anlayabilmek için öncelikle ăgda bulunan motifler üzerinde daha detaylı çalışılması gerektiği ortaya konuldu.

Anahtar Kelimeler: Biyolojik ăg, kısa-dönem bellek, sinaptik iletişim, uzun-dönem bellek, uyarıcı ve engelleyici uyaran, üç hücreli motif.

\footnotetext{
*Ahmet TURAN, aturan@kastamonu.edu.tr, https://orcid.org/0000-0001-5653-9695

Temel KAYIKÇIOĞLU, tkayikci@ktu.edu.tr, https://orcid.org/0000-0002-6787-2415
} 


\title{
Memory behavior of small-scale biological neural networks generated by generalization of a three-cell motif
}

\begin{abstract}
Many theoretical and experimental studies are performed to understand the structure and functions of biological memory. In these studies, it was seen that biological networks consisted of special intercellular connection (motifs). On the models created in the light of experimental studies, the memory structures composed of biological networks and the basic building blocks of these structures are examined. In our study, the nerve cell was modeled as a single compartment cell consisting only of soma section. Intercellular communication was preferred in the form of chemical synapses and the intercellular communication was examined in the model. Long-and short-term memory behavior was studied in three-cell motifs which were thought to be input, intermediate and output of cell roles. Long-term and short-term memory behaviors of small-scale biological networks which were formed by multiplexing of input, intermediate and output cells (motif generalization) of three-cell motifs were determined. The results of our studies in the networks consisting of motifs and motifs were compared. It was shown that the biological network exhibited the same memory behavior as its motifs. Thus, in order to understand the memory behaviors of the biological networks, it was revealed that the motifs in the network should be studied in more detail.
\end{abstract}

Keywords: Biological network, short-term memory, synaptic communication, long-term memory, excitatory and inhibitory stimuli, three-cell motif,

\section{Giriş}

Bilgiler, beyindeki sinir hücrelerinin oluşturduğu, ağ ortamında tutulmaktadır. Fakat nasıl tutulduğu henüz tam olarak anlaşılmış değildir. Biyolojik sinir ağ yapılarını tanımlamak için, deneysel ortamlarda, bazı canlıların nöral bağlantı haritaları oluşturulmuştur [1-6]. Sinir ağları; ağ motifi olarak tanımlanan ve ağda çokça görülen, özel fonksiyonlu alt ağ'lardan meydana gelir [2,3,5,7-11]. Öğrenme sürecinde, hüreler arasında yeni bağlantılar kurulmakta, bunların bazıları geçici bazıları kalıcı olmaktadır [12-16]. Öğrenme sürecini anlamak için, biyolojik çalışmalardan elde edilen veriler, hesapsal sinir bilimi tarafından kullanılmaktadır. Hesapsal nöroloji, biyolojik sinir ağlarını modellemek için, hesapsal teknikleri kullanmaktadır. Birçok çalışmada, biyolojik çalışmalardan elde edilen verilere uygun modeller kullanılmaktadır [17-19].

Biyolojik ağlardaki bellek sistemlerinin, temelde bellek yeteneğine sahip motiflerden oluştuğuna dair bulgular vardır. Bu motiflerin fonksiyonlarının anlaşılması, tüm ağların davranışlarının anlaşılması için bir adım olacaktır [15,20]. Bellek yapılarından özellikle, kısa- ve uzun dönem bellek davranışları araştırılmaktadır. Kısa dönem belleğin işleyişinden; sinir hücresi grupları arasındaki uyarı yapısının sorumlu olduğu düşünülmektedir. Bilginin uzun dönem bellekte saklanmasının ise; beyindeki nöral bağlantılarda meydana gelen, kalıcı, fonksiyonel, biyokimyasal ve yapısal değişikliklerle mümkün olabileceği düşünülmektedir [12,21-23]. Biyolojik ağlar, ağ motiflerinin giriş, çıkış ve ara hücrelerinin çoğullanması mantığına dayalı, "motif genelleme" şeklinde tanımlanan sistematik bir yaklaşımla, ortak mimari yapıya sahip, 
farklı büyüklükteki motif bağlantıları şeklinde oluşturulmaktadır [24]. Amacımız; beyinde kısa veya uzun süreli bilgi tutmanın ne şekilde gerçekleştiğini, motiflerden oluşturduğumuz ağ modeli üzerinde göstermektir. Daha gerçekçi olması için, HodgkinHuxley hücre modeli ve kimyasal sinaptik iletişim modelini tercih ettik. Literatürde, bu alanda yapılmış çalışmalarda motifler incelenirken, basitlik olması açısından motifleri oluşturan hücreler, topla-ateşle gibi basit yöntemlerle modellenmiştir. Ayrıca hücreler arası sinaptik bağ kullanılmayıp, dışarıdan gelen uyarı, hücreye gürültü akımı şeklinde uygulanmıştır $[3,25]$. Literatürde çalışılmış sınırlı sayıda motif yerine, Tablo 1'de görülen ve çizge topolojisi kullanılarak sistematik şekilde oluşturduğumuz, üç hücreli tüm motifler üzerinde çalıştık. Bu üç hücreli motiflerden, uzun dönem ve kısa dönem bellek davranışı gösterenlerden seçtiğimiz bir kaçıyla, motif genelleme yapılarak oluşturulan, küçük ölçekli biyolojik ağ yapısının bellek davranışı incelendi. Tablo 2 ve Tablo 3'de görüldügü gibi, motif genelleme yaklaşımı ile oluşturduğumuz biyolojik ağ yapılarını, uzun -ve kısa dönem bellek davranışı açısından değerlendirdik. Motiflerin ve küçük ölçekli ağların bellek davranışı gösterme durumları karşılaştırıldı.

\section{Veri ve yöntemler}

Çalışmamızda, motifleri oluşturan hücreler ve aralarındaki iletişim için, HodgkinHuxley'in deterministic bölmeli model yapısı tercih edildi [26,27]. Hücreler arası iletişim, güçlü bağlantılı sinaptik iletkenlik fonksiyonu ile modellendi. Hücreler arası uyarımlar; uyarıcı (excitatory-E) ve engelleyici (inhibitory-I) potansiyel değerlerine sahip kimyasal sinaps [25,28-32] şeklinde çalışıldı. Motifleri oluşturan hücreler, soma kısmına ait tek bölme şeklinde modellendi [32,33]. Hücreler, aldıkları uyarılara göre Şekil 1'de görülen farklı modellenir [28]. Şekil 1(a)'da görülen ve sadece dişarıdan harici akım uyarımı alan hücrenin, devre modeline ait çözüm, denklem 1'de verilmiştir [32].

$C_{m} \frac{d V_{m}}{d t}=-G_{L}\left(V_{m}-E_{L}\right)-\bar{G}_{N a} m^{3} h\left(V_{m}-E_{N a}\right)-\bar{G}_{K} n^{4}\left(V_{m}-E_{K}\right)+I_{u y g}(t)$

Çalışmalarda, sinaptik uyarı geldiğinde açılan transmitter-aktivasyonlu iyon kanalları, denklem 2'de görülen zaman bağımlı $g \operatorname{syn}(t)$ iletkenliği ile tanımlanmıştır. Diğer hücrelerden gelen uyarımın, modele eklendiği devre koluna ait akım ve birden çok uyarı alması durumundaki çözüm, denklem 3 ve 4'de gösterildi [28].

$$
\begin{aligned}
& g \operatorname{syn}(t)=g_{\max } \frac{t}{\tau} e^{\left(1-\frac{t}{\tau}\right)} \\
& I_{\text {syn }}(t)=g_{\text {syn }}(t)\left(V_{m}-E_{\text {syn }}\right) \\
& C_{m} \frac{d V_{m}}{d t}+g_{\text {rest }} V_{m}+g_{\text {syn }}{ }^{(1)}(t)\left(V_{m}-E_{\text {syn }}{ }^{(1)}\right)+g_{\text {syn }}{ }^{(2)}(t)\left(V_{m}-E_{\text {syn }}{ }^{(2)}\right)+\ldots=0
\end{aligned}
$$

Çalışmamızda, Hodgkin-Huxley'in, sinir hücresinin soma bölümünde, hücre zarı parçacığı üzerinde yaptıkları biyolojik çalışmalardan elde edilen ve yaygın bir şekilde tercih edilen parametre değerlerini kullandık. İyon kanal iletkenlikleri $\left(\bar{G}_{N a}=\right.$ $\left.120 \mathrm{mS} / \mathrm{cm}^{2}, \bar{G}_{K}=36 \mathrm{mS} / \mathrm{cm}^{2}, G_{L}=0.3 \mathrm{mS} / \mathrm{cm}^{2}\right)$, denge potansiyelleri $\left(E_{N a}=\right.$ $\left.50 \mathrm{mV}, E_{K}=-77 \mathrm{mV}, E_{L}=-54.4 \mathrm{mV}\right)$, hücre zar1 kapasitans1 $\left(C_{m}=1 \mu \mathrm{F} / \mathrm{cm}^{2}\right)$, hücre zarı dinlenme gerilimi ( $\left.V_{r}=-65 \mathrm{mV}\right)$, sinaptik denge potansiyelleri (engelleyici için $E_{\text {syn }}=-70 \mathrm{mV}$, uyarıcı için $E_{\text {syn }}=-10 \mathrm{mV}$ ), hücreler arası maksimum sinaptik iletkenlik $\left(g_{\max }=64 n S\right)$, sinaptik iletkenlik zaman sabiti $(\tau=25 \mathrm{~ms})[26,28,29] \mathrm{ve}$ 
sayısal diferansiyel denklem çözümleri için zaman adım aralığı $(\Delta t=10 \mu s)$ şeklinde seçildi. Çalışmalarda genellikle, üç sinir hücresinden oluşan motiflerin uzun -ve kısa dönem bellek davranışı incelenmiştir [34,35]. Bu çalışmada üç hücreli yönlendirilmiş tüm motiflerin elde edilmesinde, çizge topolojisi [3,24] kullanıldı. Hücrelerin; giriş (A), ara (B) ve çıkış(C) olarak değerlendirilmesi çalışmalarda kabul görmüştür [24,32]. Topolojik yöntemle elde edilen ve bu özellikleri taşıyan 42 adet motif Tablo 1'de gösterildi ve çalışmamızda değerlendirildi. Çalışmalarda kolaylık olması açısından motifler isimlendirildi, motiflerin sinaptik bağlantı yönü ve sıralaması belirtildi.

Tablo 1. Üç hücreli tüm motifler.

\begin{tabular}{|c|c|c|c|c|c|c|c|}
\hline $\begin{array}{l}\text { Motif Adı ve } \\
\text { bağlantı şekli }\end{array}$ & $\begin{array}{l}\text { Motif Şekli } \\
\text { (hücrelerin } \\
\text { uyarı yönü) }\end{array}$ & $\begin{array}{l}\text { Motif Adı ve } \\
\text { bağlantı şekli }\end{array}$ & $\begin{array}{l}\text { Motif Şekli } \\
\text { (hücrelerin } \\
\text { uyarı yönü) }\end{array}$ & $\begin{array}{c}\text { Motif Adı ve } \\
\text { bağlantı șekli }\end{array}$ & $\begin{array}{l}\text { Motif Şekli } \\
\text { (hücrelerin } \\
\text { uyarı yönü) }\end{array}$ & $\begin{array}{l}\text { Motif Adı ve } \\
\text { bağlantı șekli }\end{array}$ & $\begin{array}{l}\text { Motif Şekli } \\
\text { (hücrelerin } \\
\text { uyarı yönü) }\end{array}$ \\
\hline $\begin{array}{l}\text { MTF1 } \\
\text { B-C, A-C }\end{array}$ & & $\begin{array}{l}\text { MTF2 } \\
\text { A-B, B-C }\end{array}$ & & $\begin{array}{l}\text { MTF3 } \\
\text { A-B, A-C }\end{array}$ & & $\begin{array}{l}\text { MTF4 } \\
\text { C-A, A-C }\end{array}$ & \\
\hline $\begin{array}{l}\text { MTF5 } \\
\text { A-B, A-C } \\
\text { B-C }\end{array}$ & & $\begin{array}{l}\text { MTF6 } \\
\text { C-B, A-C } \\
\text { C-A }\end{array}$ & & $\begin{array}{l}\text { MTF7 } \\
\text { C-B, A-C } \\
\text { B-C }\end{array}$ & & $\begin{array}{l}\text { MTF8 } \\
\text { C-B, A-B } \\
\text { A-C, B-C }\end{array}$ & \\
\hline $\begin{array}{l}\text { MTF9 } \\
\text { C-B, A-C } \\
\text { B-C, C-A }\end{array}$ & & $\begin{array}{l}\text { MTF10 } \\
\text { A-B, A-C } \\
\text { B-C, C-A }\end{array}$ & & $\begin{array}{l}\text { MTF11 } \\
\text { A-B, A-C } \\
\text { B-C, B-A }\end{array}$ & & $\begin{array}{l}\text { MTF12 } \\
\text { C-B, A-C } \\
\text { B-C, C-A, B-A }\end{array}$ & \\
\hline $\begin{array}{l}\text { MTF13 } \\
\text { C-B, A-B, A-C } \\
\text { B-C, C-A, B-A }\end{array}$ & & $\begin{array}{l}\text { MTF14 } \\
\text { A-B, A-C } \\
\text { B-A }\end{array}$ & & $\begin{array}{l}\text { MTF15 } \\
\text { A-B, A-C } \\
\text { C-A, B-A }\end{array}$ & & $\begin{array}{l}\text { MTF16 } \\
\text { C-B, A-B } \\
\text { A-C, B-A }\end{array}$ & \\
\hline $\begin{array}{l}\text { MTF17 } \\
\text { A-B, A-C } \\
\text { B-C, C-A, B-A }\end{array}$ & & $\begin{array}{l}\text { MTF } 18 \\
\text { A-C, B-A }\end{array}$ & & $\begin{array}{l}\text { MTF19 } \\
\text { A-B, B-C } \\
\text { C-A }\end{array}$ & & $\begin{array}{l}\text { MTF20 } \\
\text { A-B, B-C } \\
\text { B-A }\end{array}$ & \\
\hline $\begin{array}{l}\text { MTF21 } \\
\text { C-B, A-B } \\
\text { B-C }\end{array}$ & & $\begin{array}{l}\text { MTF22 } \\
\text { C-B, A-C } \\
\text { B-C }\end{array}$ & & $\begin{array}{l}\text { MTF23 } \\
\text { C-B, A-B } \\
\text { A-C }\end{array}$ & & $\begin{array}{l}\text { MTF24 } \\
\text { A-B, A-C } \\
\text { C-A }\end{array}$ & \\
\hline $\begin{array}{l}\text { MTF25 } \\
\text { C-B, A-C }\end{array}$ & & $\begin{array}{l}\text { MTF26 } \\
\text { A-C, B-A } \\
\text { C-A }\end{array}$ & & $\begin{array}{l}\text { MTF27 } \\
\text { C-B, A-B } \\
\text { B-C, B-A }\end{array}$ & & $\begin{array}{l}\text { MTF28 } \\
\text { C-B, A-B } \\
\text { A-C, B-C, C-A }\end{array}$ & \\
\hline $\begin{array}{l}\text { MTF29 } \\
\text { C-B, A-B } \\
\text { A-C, B-C, B-A }\end{array}$ & & $\begin{array}{l}\text { MTF30 } \\
\text { C-B, A-B } \\
\text { A-C, C-A }\end{array}$ & & $\begin{array}{l}\text { MTF31 } \\
\text { C-B, A-B } \\
\text { A-C, C-A, B-A }\end{array}$ & & $\begin{array}{l}\text { MTF32 } \\
\text { C-B, A-B } \\
\text { B-C, C-A }\end{array}$ & \\
\hline $\begin{array}{l}\text { MTF33 } \\
\text { C-B, A-B } \\
\text { B-C, C-A, B-A }\end{array}$ & & $\begin{array}{l}\text { MTF34 } \\
\text { A-B, B-C } \\
\text { C-A, B-A }\end{array}$ & & $\begin{array}{l}\text { MTF35 } \\
\text { C-B, A-C } \\
\text { C-A, B-A }\end{array}$ & & $\begin{array}{l}\text { MTF36 } \\
\text { C-B, A-C } \\
\text { B-C, B-A }\end{array}$ & \\
\hline $\begin{array}{l}\text { MTF37 } \\
\text { B-C, C-A } \\
\text { B-A }\end{array}$ & & $\begin{array}{l}\text { MTF38 } \\
\text { A-C, B-C } \\
\text { C-A, B-A }\end{array}$ & & $\begin{array}{l}\text { MTF39 } \\
\text { C-B, B-C } \\
\text { C-A, B-A }\end{array}$ & & $\begin{array}{l}\text { MTF40 } \\
\text { A-C, B-C } \\
\text { B-A }\end{array}$ & \\
\hline $\begin{array}{l}\text { TMTF1 } \\
\text { A-B }\end{array}$ & ${ }_{\mathrm{A}} \bullet{ }_{\mathrm{B}}$ & $\begin{array}{l}\text { TMTF2 } \\
\text { A-B B-A }\end{array}$ & A $৫$ & & & & \\
\hline
\end{tabular}


(a)

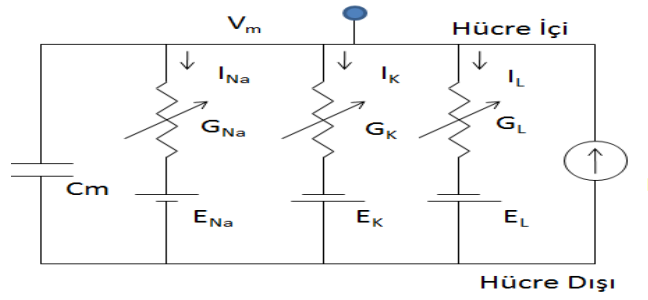

(c)

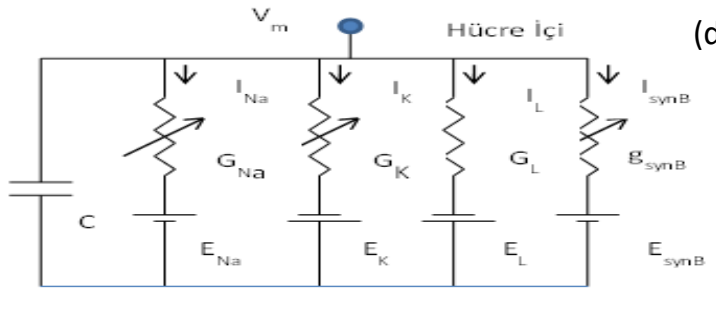

Hücre Dıșı

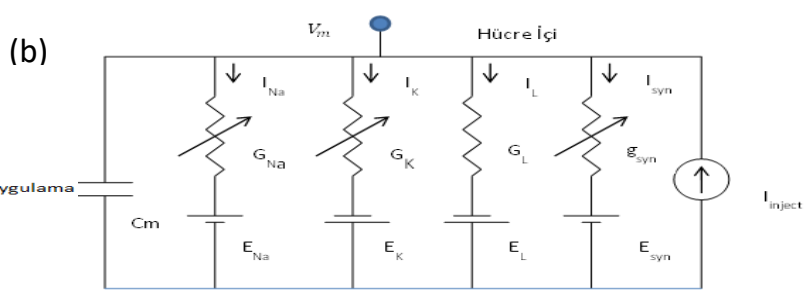

(d)

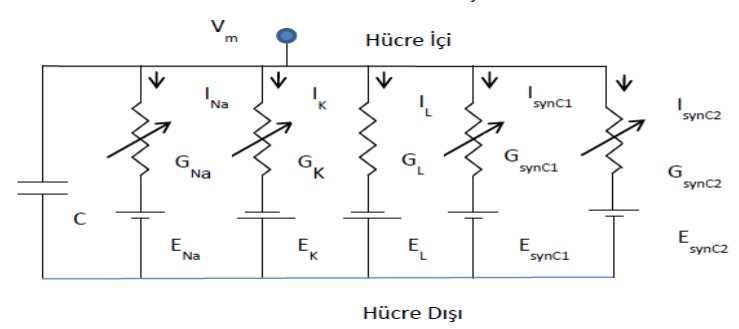

Şekil 1. (a) Harici akım uygulanan hücre modeli, (b) harici akım uygulanan ve tek sinaptik giriş alan hücre modeli, (c) sadece tek sinaptik giriş alan hücre modeli, (d) iki sinaptik giriş alan hücre modeli.

\section{Bulgular ve tartışma}

Bu çalışmada amacımız, motiflerin ve motiflerden oluşan küçük ölçekli ağların bellek özelliklerin benzerliğini belirlemektir. Bu amaçla tek hücre modelinden, motif ve biyolojik ağ yapısı modeline devam eden çeşitli uygulamalar yapıldı. Hücrenin, harici akım uyarısına cevabı, hücrelerin birbirlerini uyarma durumları, motiflerde hücrelerin birbirlerini (E veya I) uyarma şekillerinin değişken olması durumuları ve motif genelleme ile oluşturulan biyolojik ağların, uzun- ve kısa dönem bellek davranışları incelendi.

\subsection{Hodgkin-Huxley sinir hücresi modelinin uyarımlara cevabının incelenmesi}

Tek bölmeli Hodgkin-Huxley hücre modeline, hücreye birçok kaynaktan gelen ve uyarıların toplamını temsil eden, düzgün dağılımlı rastlantısal akım uyarımı yapıldı. Şekil 2(a)'da görülen böyle bir akım $0-20 \mu A$ arasında rastlantısal değerler alır. Akım Şekil 1(a)'daki modele uygulandığında, Şekil 2(b)'deki gibi uyarı akımının belli seviyelerinde, hücrede aksiyon potansiyelleri oluştu. Akım uygulaması kesildiğinde aksiyon potansiyeli üretimi de kesildi.

(a)

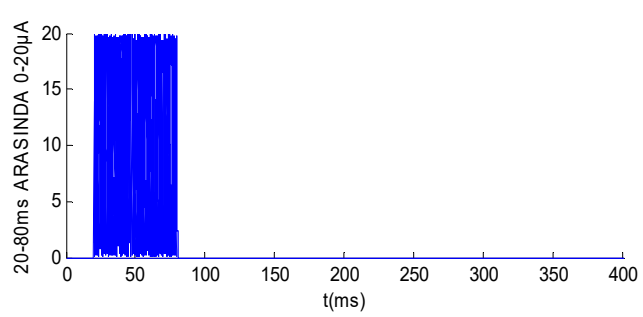

(b)

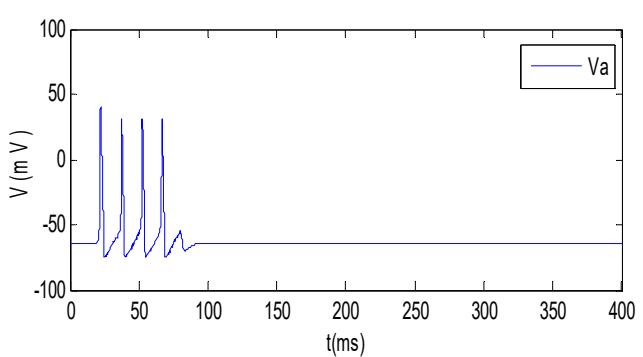

Şekil 2. (a) $0-20 \mu A$ düzgün dağılımlı rastlantısal akım, Şekil 1-a'daki hücre modeline uygulandığında (b) hücre modelinin ürettiği aksiyon potansiyelleri dizisi. 


\subsection{Karşılıklı etkileşimli iki sinir hücresi modelinin uyarımlara cevabının incelenmesi}

Tablo 1'de gösterilen TMTF2 isimli, karşılıklı etkileșimli iki sinir hücresi bağlantısı, birçok üç hücreli motif yapısı içinde görülür [3]. Böyle iki hücrenin elektriksel modeli, Şekil 1(b) ve Şekil 1(c) gösterilmişti. Şekil 1b'deki modelde A hücresi, hem harici akım, hemde B hücresi tarafından uyarılmaktadır. Şekil 1c'deki modelde ise, B hücresi sadece A hücresi tarafından uyarılmaktadır. A hücresine Şekil 2(a)'da görülen harici akım uygulandı ve A hücresinde aksiyon potansiyelleri oluştu. $\mathrm{Bu}$ durumda $\mathrm{B}$ hücresinde denklem 2'de görülen zaman bağımlı $g_{s y n B}$ iletkenliği aktif oldu. Uyarım türü (AB-EE) olduğunda B hücresinde aksiyon potansiyelleri oluştu. B hücresinde oluşan aksiyon potansiyellerinin A hücresini uyarmasından $g_{\text {syna }}$ iletkenliği aktif oldu. Uyarım türü (uyarıc1-E) olduğunda A hücresinde aksiyon potansiyellerinin desteklendiği gözlendi. A ve B hücrelerinin sürekli karşılıklı uyarımı nedeniyle, harici akım uyarımı kesilse de, aksiyon potansiyellerinin Şekil 3(a)'da görüldüğü gibi sürekli devam ettiği görüldü.

$\mathrm{Bu}$ durum, öğrenme uyarısı kesildikten sonra, bilginin bellekte tutulmaya devam ettiği, uzun-dönem bellek davranışının bir örneğidir. Şekil 3(b)' de hücreler arası uyarım (ABEI) olduğunda, A ve B hücrelerinde oluşan aksiyon potansiyellerinin, A hücresine yapılan harici akım uyarımı sona erince kesildiği gösterildi. Hücreler arası uyarım (ABIE, II) olduğunda, B hücresinde aksiyon potansiyeli üretilmedi. Bu bölümde hücreler aras1 uyarı türünün (E,I) etkisi değerlendirildi. Uyarı türünün bellek yapısının oluşumunda önemli rol oynadığı gösterildi.

(a)

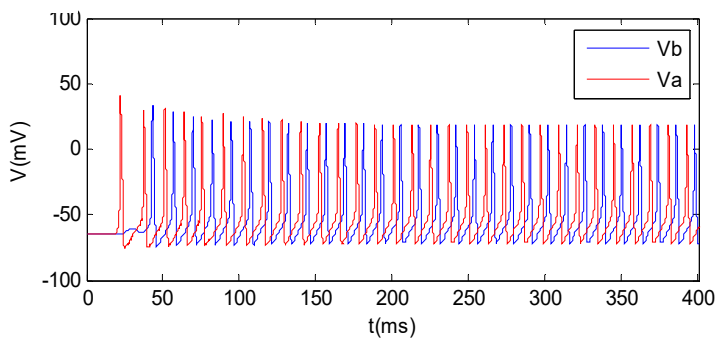

(b)

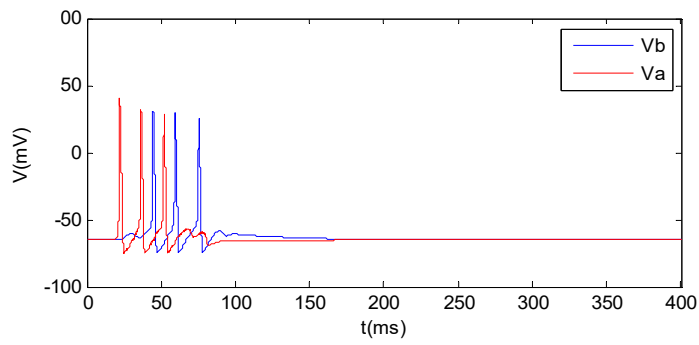

Şekil 3. TMTF2'de A hücresine Şekil 2(a)'da görülen akım uygulandığında ve uyarım türü (a) EE ve (b) EI olduğunda, A ve B hücrelerinde oluşan aksiyon potansiyelleri.

\subsection{Hücre modelinin birden fazla uyarıya cevabının incelenmesi}

Tablo 1'deki MTF1 motifinde, C hücresinin elektriksel modeli Şekil 1(d)'de gösterilmişti. Bu bağlantı şekli de birçok motif yapısı içinde görülmektedir [28,36,37]. $\mathrm{Bu}$ bölümde; A ve B hücrelerine yapılan harici akım uyarımları sonucu, hücrelerde oluşan aksiyon potansiyelleriyle uyarılan $\mathrm{C}$ hücresinde, birden fazla sinaptik uyarımın etkisi incelendi. Şekil 4(a)'da, sadece A hücresine $10 \mu \mathrm{A}$ DC akım uygulandı ve C hücresinde, frekansı $68 \mathrm{~Hz}$ olan aksiyon potansiyelleri gözlendi (C hücresini uyarım türü, AB-EE). Aynı akım, A ve $\mathrm{B}$ hücrelerinin her ikisine uygulandığında, $\mathrm{C}$ hücresinde, iki sinaptik uyarımın toplamı etkisinden, Şekil 4(b)'de görülen, frekans1 $72 \mathrm{~Hz}$ olan bir cevap oluştu. Uyaran arttıkça oluşan aksiyon potansiyellerinin frekans1 artarken genliği düşmektedir. Çoklu uyarı sayısı arttıkça, çıkışta, aksiyon potansiyeli özelliği taşımayacak şekilde genlik değeri düşmektedir. Şekil 4(c)'de C hücresini uyarı türü (AB-EI) olduğunda iki uyarının birbirini söndürdügü görüldü. 
(a)

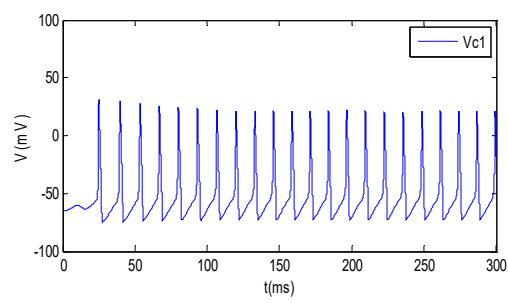

(b)

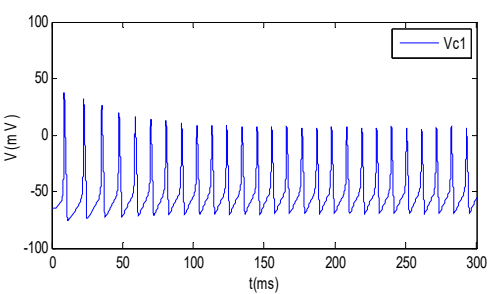

(c)

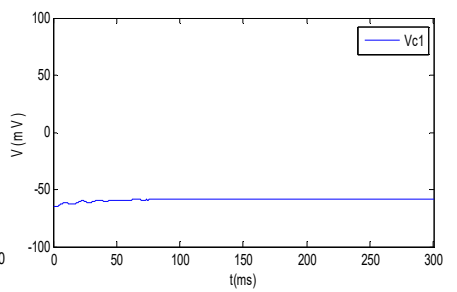

Şekil 4. MTF1'de 10 $\mu A^{\prime}$ 'lik DC akım (a) A hücresine (b) A ve B hücrelerine (uyarım, $\mathrm{AB}-\mathrm{EE}$ ) (c) A ve B hücrelerine (uyarım, $\mathrm{AB}-\mathrm{EI}$ ) uygulandığında, $\mathrm{C}$ hücresinin cevabı.

Bu çalışmada, birden fazla uyarı alan C hücresi, (uyarım-E olduğunda) daha yüksek frekanslarda çıkış üretti. Farklı tür uyarımlarda (E,I) ise birbirlerinin söndürecek şekilde sönümleştiği gösterildi.

\section{4. Üç hücreli motif'lerde uzun-ve kısa dönem bellek davranışının incelenmesi}

Tablo 1'deki tüm motifler, kısa -ve uzun dönem bellek davranışı yönünden incelendi. MTF11 ve MTF8 üzerinde yapılan bazı uygulamalar, Şekil 5 ve Şekil 6'da gösterildi. Bu çalışma tüm motiflere uygulandı. MTF11'de tüm sinaptik uyarımlar (E) seçildi ve A hücresine, SSekil 2(a)'daki akım uygulandı. Akım uygulaması $80 \mathrm{~ms}$ sonunda kesilse de, C çıkış hücresinde, Şekil 5(a)'da görülen aksiyon potansiyelleri oluşmaya devam etti. Motif, veriyi sürekli hafızasında tutarak uzun-dönem bellek davranışı gösterdi. Uyarı akımı rastlantısal olduğundan, her uyarımda aksiyon potansiyeli üretme zamanları farklılık gösterdi. Bu farklılı̆̆ 1 ortaya koymak için $50 \mathrm{kez}$ aynı uygulama tekrar edildi ve her denemede $\mathrm{C}$ hücresinde oluşan aksiyon potansiyeli oluşma zamanları grafik üzerinde gösterildi.

(a)

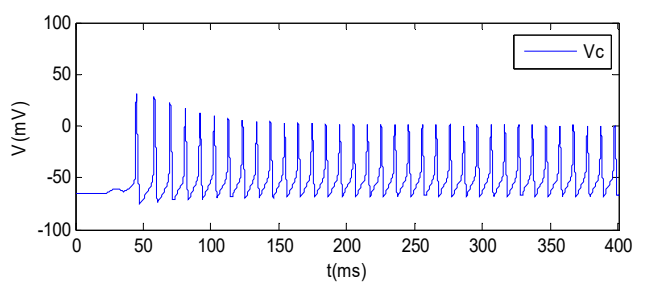

(b)

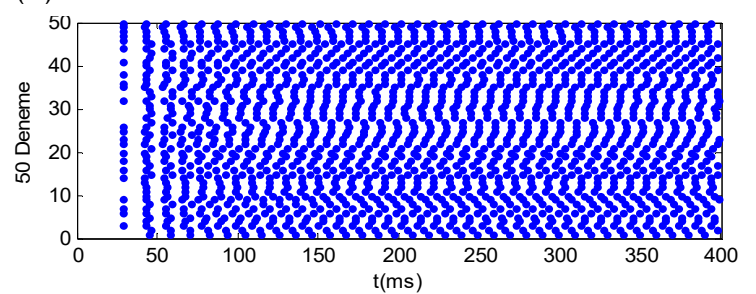

Şekil 5. MTF11'de C hücresine (uyarım-E) seçilerek, A hücresine Şekil 2.a'daki akım uygulandiğında (a) C hücresinde oluşan aksiyon potansiyelleri (b) 50 deneyin her biri için $\mathrm{C}$ hücresinde aksiyon potansiyeli tepe değerlerinin zamanları.

MTF8'de, A hücresine Şekil 2(a)'da görülen akım 400ms süreyle, 50 kez tekrarlanarak uygulandığında (uyarım-E), C hücresinde Şekil 6(a)'da görülen aksiyon potansiyel dizileri üretildi. Bu şartlarda motif uzun-dönem bellek davranışı gösterdi. Aynı motifte hücre uyarımları (ABC-EEI) yapıldığında, Şekil 6(b)'de görüldüğü gibi, harici akım uyarımı $80 \mathrm{~ms}$ sonunda kesildikten sonra, yaklaşık 60ms süreyle $\mathrm{C}$ hücresinde aksiyon potansiyeli üretilmeye devam etti. 
a)

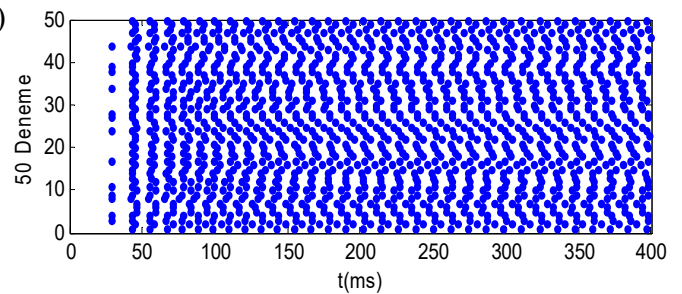

b)

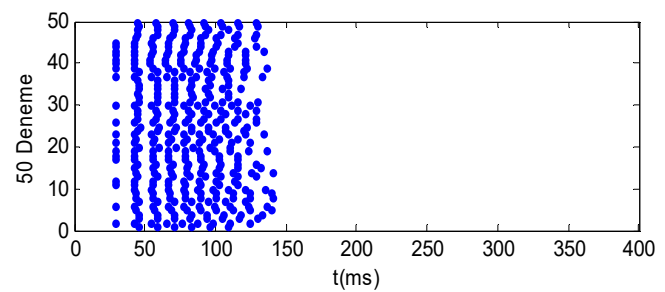

Şekil 6. MTF8'de A hücresine Şekil 2(a)'daki akım uygulandığında; (a) (Uyarımlar-E) olduğunda ve (b) (Uyarımlar, $\mathrm{ABC}$-EEI) olduğunda $\mathrm{C}$ hücresinde 50 deneyin her biri için aksiyon potansiyeli zamanları.

Dikkat edilirse motif, uyarı bittikten sonra bilginin bir süre daha tutulup unutulması şeklinde davranan, kısa-dönem bellek özeliği göstermiş oldu. Uyarı türünün değişimiyle motifin hem uzun hem de kısa dönem bellek olabildiği ortaya konuldu.

\subsection{Uzun - ve Kısa dönem bellek davranışı gösteren motifler}

Tablo 1'de görülen motiflerin tümüne, Bölüm 3.4'deki çalışmalar uyguland1. Hücrelerin uyarıcı (E) veya engelleyici (I) uyarması durumlarının tüm olasılıkları çalışıldı. Bazı motiflerin uyarı türüne bağlı olarak uzun-dönem bellek davranışı sergilediği gözlendi. (TMTF2, MTF4, MTF6-MTF17, MTF19-MTF22, MTF24, MTF26-MTF36 aralığ1 ve MTF38 motifleri). Bu motiflerin ortak yanı, üç hücre arasında $C$ hücresine varan kapalı bir döngü olmasıdır (A-C, B-C, A-B-C şeklinde). Bu şekilde üç hücreli uzun dönem bellek davranışı gösteren motifler ve özellikleri belirlendi.

Tablo 1'deki motiflerde, tüm uyarı türleri (E,I) için kısa-dönem bellek davranış1 incelendi. Bazı motiflerin uyarı türüne bağlı olarak kısa dönem bellek davranışı gösterdiği belirlendi. (MTF5-MTF7, MTF9, MTF11-MTF13, MTF15, MTF17, MTF19, MTF20, MTF22, MTF26, MTF28-MTF31, MTF33-MTF36, MTF38 ve MTF40 motifleri).

Çalışmamızda; bazı motiflerin, uyarım türüne bağlı olarak, hem uzun hem de kısa dönem bellek özelliği göstermesi, uyarım türünün bellek yapılarında çok önemli bir parametre olduğunu göstermiş oldu.

3.6. Motif genelleme ile oluşturulan, küçük ölçekli biyolojik sinir ăglarının, bellek davranışının incelenmesi

Motiflerin, ağ içerisinde aynı davranışları segilediğini göstermek için, önceki çalışmadan uzun -ve kısa dönem bellek davranışı gösterdiği belirlenen MTF8, MTF32 ve MTF35 motifleri, sistematik bir yöntemle Tablo 2'de görüldüğü gibi genellendi. Elde edilen küçük ölçekli ağların bellek davranışını belirlemek için, motiflere yapılan çalışmalar tekralandı. Motif genelleme yapılırken, A,B,C hücreleri 2,3,5 adet şeklinde çoklandı. Küçük ölçekli ağlar üzerinde yapılan çalışmalardan elde edilen bulgular Tablo 3 ve Tablo 4`de gösterildi. 
Tablo 2. Tablo 1'deki MTF8 ve MTF32'in giriş, ara ve çıkış hücrelerinin 2, 3 ve 5 hücre olacak şekilde çoğullanmış şekli.

\begin{tabular}{|c|c|c|c|c|c|c|}
\hline $\begin{array}{l}\text { Temel Motif } \\
\text { MTF8 }\end{array}$ & \begin{tabular}{|l} 
Motif \\
Adı
\end{tabular} & Motif Șekli & $\begin{array}{l}\text { Motif } \\
\text { Adı }\end{array}$ & Motif Șekli & $\begin{array}{l}\text { Motif } \\
\text { Adı }\end{array}$ & Motif Șekli \\
\hline & 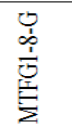 & & 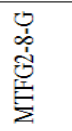 & & 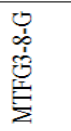 & \\
\hline & 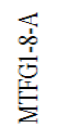 & B1 & 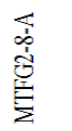 & & 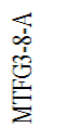 & \\
\hline & 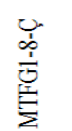 & & 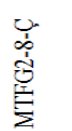 & & 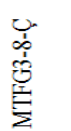 & \\
\hline
\end{tabular}

\subsubsection{Uzun dönem bellek davranışının incelenmesi}

MTF8 ve MTF32'nin genelleştirilmiş modellerinde, motiflere yapılan çalışmalar tekrarlandı. Şekil 1(a)'da görülen akım, farklı büyüklüklerde, A hücrelerine uygulandı (uyarım türü-E). Bu şartlarda birçok akım değerinde biyolojik ağ yapılarının uzun dönem bellek davranışı sergilediği gözlemlendi. Tablo 3'de; 2 ve 5 hücre şeklinde çoğullanmış motif tabanlı ă̆ yapısının, uzun dönem bellek davranışı sergilediği akım değerleri verildi. MTF8'in, giriş hücreleri 2 ve 5 hücre şeklinde çoğullanmış ağ yapısıyla, oldukça ortak davranışlar sergilediği görüldü.

Tablo 3'den de görüleceği gibi, girişler çoğaldığında daha düşük akımlarda da, hücreler toplamsallık etkisiyle aksiyon potansiyelleri üretebilmektedir. MTF32'de olduğu gibi A giriş hücresine geri besleme olduğunda, çok yüksek akımlarda yığılma olduğundan aksiyon potansiyeli üretilememektedir. Ayrıca hücreye aynı anda gelen çok fazla uyarıdan kaynaklanan kayıplar gözlendi. Bunun nedeni; modele verdiğimiz uyarıların, bir hücrenin dentritlerine gelen toplam uyarıyı ifade eden akımlar olmasıdır. Bu uyarılardan çok sayıda uyguladığımızda, modeldeki paralel kol sayısının artmasından dolayı, bir doyum oluşmakta ve frekans aşırı derecede artıp genlik düşmektedir. Siyallerin genliği aksiyon potansiyeli olma eşiğinin altına düşmektedir. Bu durumda deneylerde giriş akım büyüklüğü önem arzetmektedir. Bu nedenle bazı çalışmalarda, akım genliği düşürülerek uyguland1.

Tablo 3. MTF8, MTF32 motiflerinin genelleştirilmiş modellerinde uzun-dönem bellek davranışı görülen durumlar( A hücresine 5-85 $\mu \mathrm{A}$ arasında 2,5 $\mu \mathrm{A}$ artan değerlerde harici akımlar uyguland1)

\begin{tabular}{|l|l|l|l|}
\hline Motif Ad1: MTF8 & $\begin{array}{l}\text { Uzun Dönem Bellek davranış1 } \\
\text { görülen harici akım büyüklüğu }\end{array}$ & Motif Ad1: MTF32 & $\begin{array}{l}\text { Uzun Dönem Bellek davranış1 } \\
\text { görülen harici akım büyüklüğu }\end{array}$ \\
\hline & $15-50,55-62.5 \mu \mathrm{A}$ Aras1 & $15-20,30-35 \mu \mathrm{A}$ Aras1 \\
\hline
\end{tabular}


Tablo 3. (Devami).

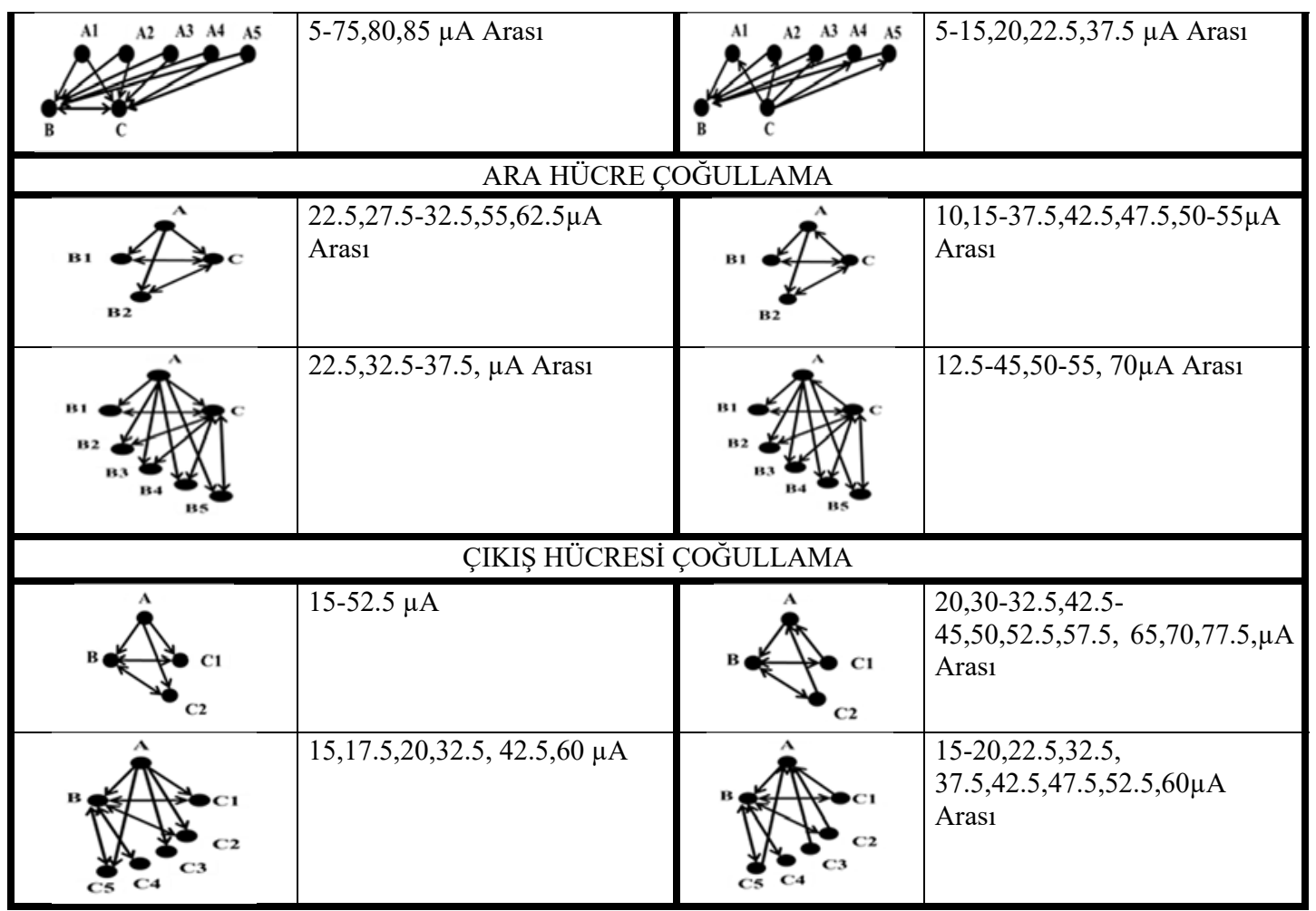

Çalışmanın bu bölümünde, birçok harici akım değerinde, motifle küçük ölçekli ağ’’n aynı davranışı sergilediği görüldü.

\subsubsection{Kısa dönem bellek davranışının incelenmesi}

Çalışmanın bu bölümünde, MTF8 ve MTF35'in genelleştirilmiş modellerinde, bölüm 3.4'deki motiflere uygulanan çalışmalar tekrarlandı. Hücrelerin uyarı şekli, Tablo 4'deki gibi seçilerek, Şekil 1(a)'da görülen akım, (genlik 30 $\mu A$ ) girişe uygulandı ve genelleştirilmiş biyolojik ağ yapılarının kısa-dönem bellek davranışı incelendi. Tablo 4'de biyolojik ağ yapısının ve motif' in; C Çıkış hücresinde oluşan aksiyon potansiyeli sayıs1 (AKPS), aksiyon potansiyeli frekansı (AKPSF) ve aksiyon potansiyeli standart sapma değerleri karşılaştırıldı. Bu verilerin yakınlığı; motif ve küçük ölçekli ağ yapısının, kısa-dönem bellek davranışlarının benzer olduğunu gösterdi. Motifin yapısına bağlı olarak, özellikle giriş hücreleri çoklandığında ortaya çıkan en büyük sorun, fazla uyarının oluşturduğu yığılmadır (Motif 35' de iki geri besleme olduğundan, çıkış hücre çoğullaması olduğunda da bu durum oluşmaktadır). Bu etkiden dolayı, motifin yapısına da bağlı olarak, aksiyon potansiyeli özelliği olmayan çıkışlar oluşmaktadır. Tablo 4'de artan standart sapma değerleri, bu kayılar nedeniyle oluşmuştur. $\mathrm{Bu}$ problemi çözmek için, uyarı adediyle orantılı olarak uyarı büyüklüğünde oransal düşmeler yapılmasının, daha doğru olacağı değerlendirildi. Buna örnek olarak, MTF8 hücresinin giriş çoğullama çalışmasında, giriş hücre sayısı arttıkça uyarı genliğini düşürdük. 
Tablo 4. MTF8, MTF35'in ve bu motiflerin genelleştirilmiş modellerinin, kısa-dönem bellek davranışı gösterdiği durumlar.

\begin{tabular}{|c|c|c|c|c|c|}
\hline MOTİFLER & Uyarı durumu & Ak1m $(\mu \mathrm{A})$ & AKPS & $\mathrm{AKPF}(\mathrm{Hz})$ & STDS \\
\hline MTF8 & IIEE & 30 & 9 & 79 & 0.99 \\
\hline \multicolumn{6}{|l|}{ Giriş hücre genelleme } \\
\hline MTF8GG 3-H & IIEE & 30 & 10 & 76 & 1.2 \\
\hline MTF8GG_5-H & IIEE & 20 & 12 & 69 & 1.39 \\
\hline MTF8GG_8-H & IIEE & 20 & 10 & 88 & 3.4 \\
\hline \multicolumn{6}{|l|}{ Ara hücre genelleme } \\
\hline MTF8GA 3-H & IIEE & 30 & 11 & 74 & 1.35 \\
\hline MTF8GA 5-H & IIEE & 30 & 7 & 77 & 0.64 \\
\hline MTF8GA 8-H & IIEE & 30 & 11 & 68 & 1.5 \\
\hline \multicolumn{6}{|l|}{ Çıkış hücre genelleme } \\
\hline MTF8GC_3_H & IIEE & 30 & 12 & 78 & 1.87 \\
\hline MTF8GC $5 \mathrm{H}$ & IIEE & 30 & 12 & 75 & 1.75 \\
\hline MTF8GC_8_H & IIEE & 30 & 10 & 75 & 1.07 \\
\hline MTF35 & EEEI & 30 & 10 & 80 & 0.78 \\
\hline \multicolumn{6}{|l|}{ Giriş hücre genelleme } \\
\hline MTF35GG 3-H & EEEI & 30 & 8 & 83 & 1 \\
\hline MTF35GG 5-H & EEEI & 30 & 9 & 89 & 1.2 \\
\hline MTF35GG_8-H & EEEI & 30 & 6 & 91 & 0.97 \\
\hline \multicolumn{6}{|l|}{ Ara hücre genelleme } \\
\hline MTF35GA 3-H & EEEI & 30 & 7 & 74 & 0.8 \\
\hline MTF35GA_5-H & EEEI & 30 & 6 & 68 & 1.17 \\
\hline MTF35GA_8-H & EEEI & 30 & 7 & 69 & 1.75 \\
\hline \multicolumn{6}{|l|}{ Çıkış hücre genelleme } \\
\hline MTF35GC 3_H & EEEI & 30 & 15 & 74 & 0.82 \\
\hline MTF35GC $5 \mathrm{H}$ & EEEI & 30 & 10 & 69 & 1.2 \\
\hline MTF35GC $8 \mathrm{H}$ & EEEI & 30 & 18 & 75 & 5.7 \\
\hline
\end{tabular}

Tüm bu çalışmalarda elde edilen sonuçlardan, motiflerin yapılarına bağlı olarak, çoğullama ile oluşturulan ağ yapılarının bellek davranışları gösterildi. Bilginin saklandığı beyin bölümleriyle ilgili bir yorum ortaya konuldu. Literatürde yapılmış çalışmalar motif yapıları üzerindedir. Çalışmamızda, beyinde bilgi tutan en küçük birim olduğu düşünülen motiflerin, ağ ortamında aynı özelliklere sahip oldukları gösterildi. Ayrıca bu modeller çok daha büyütülerek bilgi tutulması esnasında beyindeki hücreler arası iletişim modellenebilecektir.

\section{Sonuç}

$\mathrm{Bu}$ çalışmada, üç hücreli motifler ve motiflerden oluşan küçük ölçekli ağlar üzerinde yapılan çalışmalardan elde edilen bulgular değerlendirildi. Motiflerin kısa- ve uzun dönem bellek davranışının, hücrelerin uyarıcı (E) veya engelleyici (I) uyarımına ve motifin yapısına bağlı olduğu ortaya konuldu. Ardından, motiflerin, dışarıdan bir süre uygulanıp kesilen bilgiyi tutma zamanları değerlendirilerek, kısa- ve uzun dönem bellek davranışı gösterdikleri durumlar tespit edildi. Ayrıca, üç hücreli motiflerden hangilerinin, hangi şartlarda bellek davranışı sergiledikleri tespit edilerek sınıflandırıldı. $\mathrm{Bu}$ motiflerin tespitinden sonra, bellek davranış1 gösteren motiflerden, motif genelleme ile elde edilen küçük ölçekli biyolojik ağların bellek davranışları incelendi. Motiflerin, tek olarak gösterdikleri bellek davranışlarını, biyolojik ağ ortamında da sergilediği gösterildi. Oluşturulan yazılım modellemesiyle, biyolojik ağların ve onları oluşturan motiflerin, aynı şartlarda kısa- ve uzun dönem bellek davranışı sergilediği gösterildi. $\mathrm{Bu}$ çalışmayla; tüm üç hücreli motiflerin ve motif genelleme ile oluşturulan küçük 
ölçekli ağların modellerinde, motif-ağ ilişkisi ortaya konularak, literatüre katkıda bulunuldu.

(Kısa-ve uzun dönem bellek davranışı gösteren motiflerle ilgili çalışmamız 2014 yılında "Uzun dönem ve kısa dönem bellek davranışı gösteren nöronal motifler" ismiyle bildiri olarak sunulmuştur.)

\section{Kaynaklar}

[1] Humphries, M. D., Dynamical networks: Finding, measuring, and tracking neural population activity, Massachusetts Institute of Technology, 1,4, 324338, (2017).

[2] Cornelia, I.B. ve Eve, M., From the connectome to brain function, Nature America, (2013).

[3] Li, C., Functions of neuronal network motifs, Physical reviewe E, 037101, (2008).

[4] Prill, R.J, Iglesias, P.A. ve Levchenko, A., Dynamic properties of network motifs contribute to biological network organization, PLOS Biology, (2005).

[5] Sporns, O. ve Kotter, R., Motifs in Brain Networks, PLOS Biology, (2004).

[6] Gorochowski T.E., Grierson, C.S., Bernardo, M., Organisation of feed-forward loop motifs reveals architectural principles in natural and engineered networks, Biorxiv The preprint server for biology, (2017).

[7] Dong, C.Y., Lim, J., Nam, Y. ve Cho, K.H., Systematic analysis of synchronized oscillatory neuronal networks reveals an enrichment for coupled direct and indirect feedback motifs, Bioinformatics, 25, 13, 1680-1685, (2009).

[8] Heinz, K. ve Stefan, H., Motifs, algebraic connectivity and computational performance of two data-based cortical circuit templates, International Workshop on Computational Systems Biology, (2009).

[9] Kim, J.R., Yoon, Y. ve Cho, K.H., Coupled feedback loops form dynamic motifs of cellular networks, Biophysical Journal 94, 359-365, (2008).

[10] Song, S., Sjöström, P.J., Reigl, M., Nelson, S. ve Chklovskii, D.B., Highly nonrandom features of synaptic connectivity in local cortical circuits, PLOS Biology, (2005).

[11] Feldmeyer, D., Qi, G., Emmenegger, E. ve Staiger, J.F., Inhibitory Interneurons and their Circuit Motifs in the Many Layers of the Barrel Cortex, Neuroscience, Published by Elsevier Ltd, (2018).

[12] Chenkov, N., Sprekeler, H. ve Kempter, R., Memory replay in balanced recurrent networks, PLoS Computational Biology 13(1): e1005359, (2017).

[13] Dong, C.Y., Lim, J., Nam, Y. ve Cho, K.H., Systematic analysis of synchronized oscillatory neuronal networks reveals an enrichment for coupled direct and indirect feedback motifs, Bioinformatics, 25, 13, 1680-1685, (2009).

[14] Elodie, B.J., Sabrina, D. ve Serge, L., Brain plasticity mechanisms and memory, A Party of Four Neuroscientist, 13, 492, (2007).

[15] Kaiser, T.F. ve Peters, F.J., Synaptic Plasticity, Nova science publishers, New York, (2009).

[16] Mark, M., Steven, A.S. ve Eric, R.K., Synapses and memory storage, Cold Spring Harb Perspect Biology, (2012).

[17] Arbib, M.A., The handbook of brain theory and neural network, (Second edition), (2003). 
[18] Bassett, D.S. ve Bullmore E., Small-World Brain Networks Revisited, The Neuroscientist, 23(5), 499-516, (2017).

[19] Khambhati, A.N, Sizemore, A.E., Betzel, R.F. ve Bassett, D.S, Modelling and Interpreting Network Dynamics, Biorxiv The preprint server for biology, ( 2017).

[20] Tang, E., Bassett, D.S, Control of Dynamics in Brain Networks, Reviews of modern physics, (2017).

[21] Keleş, E. ve Çepni, S., Beyin ve Öğrenme, Journal of Turkish Science, (2006).

[22] Mirisis, A.A., Alexandrescu, A., Carew, T.J. ve Kopec A.M., The Contribution of Spatial and Temporal Molecular Networks in the Induction of Long-term Memory and Its Underlying Synaptic Plasticity, Neuroscience, (2016).

[23] Spiegler, A., Hansen E., Bernard, C., McIntosh, A.R. ve Jirsa, V.K., Selective Activation of Resting-State Networks following Focal Stimulation in a ConnectomeBased Network Model of the Human Brain, Eneuro, (2016).

[24] Junker, B.H. ve Schreiber, F., Analysis of biological networks, (2008).

[25] Thurley, K., Wu, L.F. ve Altschuler, S.J., Response-time behaviors of intercellular communication network motifs, Biorxiv The preprint server for biology, (2017).

[26] Wang, J., Jianming, G.J. ve Fei, X., Two-parameters hopf bifurcation in the Hodgkin-Huxley model, Chaos, Solitons \& Fractals: X, 23, 973-980, (2005).

[27] Schachinger, D., Simulation of extracellularly recorded activities from small nerve formations in the brain, Thesis, Wien, Mai, (2003).

[28] Bower, J.M. ve Beeman, D., The Book of GENESIS (Second edition), Springer-Verlag, (1998).

[29] Gerstner, W. ve Kistler, W.M., Spiking neuron models, Cambridge University Press, (2002).

[30] Keener, J. ve Sneyd, J., Mathematical physiology (Second Edition), ( 2009).

[31] Jackman S.L., Regehr W.G., The Mechanisms and Functions of Synaptic Facilitation, Neuron, 94,3,447-464, (2017).

[32] Dayan, P. ve Abbott, L.F., Theoretical neuroscience, (2002).

[33] Izhikevich, E.M., Dynamical systems in neuroscience, The MIT Press Cambridge, 16-17, (2007).

[34] Milo, R., Shen, O.S., Itzkovitz, S., Kashtan, N., Chklovskii, D. ve Alon, U., Network motifs simple building blocks of complex networks, Science, 298, 824827, (2002).

[35] Bassett, D.S. ve Bullmore, E., Small-world brain networks, The Neuroscientist, 512-523, (2006).

[36] Han, Z., Vondriska, T.M., Yang, L., Maclellan, W.R., Weissa, J.N. ve Qu, Z., Signal transduction network motifs and biological memory, Journal of Theoretical Biology, 246, 755-761, (2007).

[37] Navlakha, S., Joseph, Z.B. ve Barth, A.L., Network Design and the Brain, Trends in cognitive sciences, 64-78, 22, 1, 67-78, (2018). 